Jurnal Media Pertanian Vol. 3 No. 1 Tahun 2018 Hal. 1 - 9

Media Komunikasi Hasil Penelitian dan Review Literatur Bidang Ilmu Agronomi ISSN print $2503-1279$

ISSN online $2581-1606$

\title{
TANAMAN PINANG DAN KELAPA SISTEM TUMPANG SARI
}

\author{
Nasamsir ${ }^{1)}$ dan Irman $^{2)}$ \\ ${ }^{1)}$ Prodi Agroteknologi, Fakultas Pertanian Universitas Batanghari \\ ${ }^{2}$ Alumni Prodi Agroteknologi Fak.Pertanian Univ. Batanghari \\ Jl. Slamet Riyadi, Broni Jambi, 36122. Telp. +6274160103 \\ 1)email korensponden: nasamsirsamsir@yahoo.co.id
}

\begin{abstract}
Multiple cropping is a plant cultivation system that can increase the productivity of land. This increase can be measured by the scale of the Land Equivalence Ratio (LER). The aim of this research is to observe the growth and production of intercropping areca plant with coconut plant, to determine the value of land equivalence ratio (LER) and to determine the model of intercropping of areca plant with coconut plant. This research was conducted in Sabak Ulu sub-district and in Siao Dalam village, Muara Sabak Timur sub-district of Tanjung Jabung Timur district from June to July 2017 with peat land condition. This research used survey method on farmers' lands planted monoculture and intercropping with areca plants and coconut plant. The observed parameters include planting distance $(\mathrm{m})$, plant height $(\mathrm{m})$, stem circumference $(\mathrm{cm})$, production starting age $(y r)$, productivity of the areca plants and coconut plant in intercropping (ton ha ${ }^{-1}$ ), productivity of areca plants and coconut plant in monoculture (t ha-1), and land productivity (LER). To answer the proposed hypothesis, the data obtained in the field is done statistical analysis with descriptive method in the form of tabulation.

The results showed that the production of areca and coconut plants in monoculture system is greater than the intercropping system. Based on the calculation of the value of land equivalence ratio (LER) shows the value of more than 1, illustrates that the intercropping system is more profitable than monoculture system.
\end{abstract}

Keywords ; crop production, land equivalence ratio, intercropping

\begin{abstract}
Abstrak
Tumpang sari merupakan sistem budidaya tanaman yang dapat meningkatkan produktivitas lahan. Peningkatan ini dapat diukur dengan besaran Nisbah Kesetaraan Lahan (NKL) atau LER (land Equivalent Ratio). Penelitian ini bertujuan untuk mengamati pertumbuhan dan produksi tanaman tumpang sari Pinang dengan Kelapa Dalam, menentukan nilai nisbah kesetaraan lahan (NKL) serta menentukan model tanam tumpang sari Pinang dengan Kelapa Dalam yang baik. Penelitian ini dilakukan di kelurahan Sabak Ulu serta di desa Siao Dalam kecamatan Muara Sabak Timur kabupaten Tanjung Jabung Timur bulan Juni sampai bulan Juli 2017 dengan kondisi lahan gambut. Penelitian ini menggunakan metode survey pada lahan-lahan petani yang ditanami Pinang monokultur dan Pinang tumpang sari dengan Kelapa Dalam. Parameter yang diamati meliputi jarak tanam $(\mathrm{m})$, tinggi tanaman $(\mathrm{m})$, lingkar batang $(\mathrm{cm})$, umur mulai produksi (th), produktivitas buah Pinang dan Kelapa secara tumpang sari $\left(\mathrm{t} \mathrm{ha}^{-1}\right)$,
\end{abstract}

Diterbitkan oleh Program Studi Agroteknologi Fakultas Pertanian Universitas Batanghari Jambi Halaman 1 
Jurnal Media Pertanian Vol. 3 No. 1 Tahun 2018 Hal. 1 - 9

Media Komunikasi Hasil Penelitian dan Review Literatur Bidang Ilmu Agronomi ISSN print $2503-1279$ ISSN online $2581-1606$

produktivitas buah Pinang dan Kelapa tunggal $\left(\mathrm{t} \mathrm{ha}^{-1}\right)$, dan produktivitas lahan (NKL). Untuk menjawab hipotesis yang diajukan, data dianalisis secara deskriptif dalam bentuk tabulasi. Hasil penelitian menunjukkan produksi tanaman Pinang dan Kelapa Dalam sistem tunggal lebih besar dari sistem tumpang sari Berdasarkan perhitungan nilai nisbah kesetaraan lahan (NKL) menunjukan nilai lebih dari 1, menggambarkan bahwa sistem tumpang sari lebih menguntungkan dibandingkan sistem tunggal.

Kata kunci ; produksi tanaman, nisbah kesetaraan lahan, tumpang sari

\section{PENDAHULUAN}

Tanaman pinang (Areca catechu L.) sudah dimanfaatkan sejak lama terutama daerah-daerah Asia Selatan dan Timur sampai daerah Kepulaun Pasifik. Tanaman ini sudah menyebar di seluruh pelosok wilayah Indonesia, namun, dibanding dengan komoditas perkebunan lainnya yang dapat memberikan devisa Negara, pinang masih ketinggalan (Muin, 2015).

Pinang termasuk family Palmaceae yang dimanfaatkan sebagai bahan baku industri farmasi. Penyebaran terbesar dan sekaligus sebagai daerah pengekspor biji Pinang terdapat di Pulau Sumatra, antara lain Provinsi Aceh dan Jambi. Sementara daerah lain masih terbatas untuk konsumsi lokal. Tanaman Pinang merupakan komoditas unggulan perkebunan Provinsi Jambi di samping komoditas tanaman perkebunan yang lain, seperti : tanaman kelapa sawit, karet, kelapa dan kakao (Dinas Pertanian Tanaman Pangan Provinsi Jambi, 2014).

Kelapa Dalam (Cocos nucifera L.) merupakan tanaman yang sangat dekat dengan kehidupan masyarakat Indonesia, dari sejak manusia dilahirkan hingga kematiannya. Begitu dekatnya maka tanaman kelapa dalam dijuluki sebagai tanaman kehidupan. Tanaman kelapa dalam diperlukan masyarakat umumnya sebagai kelapa butiran dan minyak goreng. Diluar Jawa kelapa pada umumnya diolah menjadi kopra. Namun bagi masyarakat Jawa Timur kelapa dalam sebagian besar digunakan sebagai kebutuhan rumah tangga, minuman penyegar, dan bagian lainnya dimanfaatkan sebagai bahan baku kerajinan (Disbun Prov. Jatim, 2012).

Berdasarkan data Dirjen Perkebunan Kementerian Pertanian pada tahun 2015 luas areal dan produksi Pinang pada tiap Provinsi di Sumatera dapat dilihat pada Tabel 1 .

Tabel 1. Luas dan Produksi tanaman pinang menurut Provinsi di Sumatra pada tahun 2015.

\begin{tabular}{cccc}
\hline No & Provinsi & $\begin{array}{c}\text { Luas Areal } \\
(\mathrm{Ha})\end{array}$ & $\begin{array}{c}\text { Produksi } \\
(\text { Ton })\end{array}$ \\
\hline 1 & Jambi & 19.967 & 13.482 \\
2 & Aceh & 41.065 & 27.439 \\
3 & Riau & 18.698 & 7.301 \\
4 & Sumatera Barat & 10.252 & 7.259 \\
5 & Sumatera Utara & 5.917 & 2.683 \\
6 & Sumatera Selatan & 15.83 & 905 \\
7 & Bengkulu & 2.357 & 866 \\
\hline \multicolumn{4}{c}{114.086} \\
\hline
\end{tabular}

Sumber:Direktorat Jenderal Perkebunan, 2015 
Jurnal Media Pertanian Vol. 3 No. 1 Tahun 2018 Hal. 1 - 9

Media Komunikasi Hasil Penelitian dan Review Literatur Bidang Ilmu Agronomi ISSN print $2503-1279$

ISSN online $2581-1606$

Berdasarkan data Statistik Perkebunan Provinsi Jambi pada tahun 2015 luas areal, produksi dan produktivitas Pinang pada tiap kabupaten di Provinsi Jambi dapat dilihat pada Tabel 2.

Tabel 2. Luas, produksi dan produktivitas tanaman Pinang di Provinsi Jambi menurut Kabupaten pada tahun 2015.

\begin{tabular}{lcccc}
\hline \multicolumn{2}{l}{ NoKabupaten } & $\begin{array}{c}\text { Luas Areal } \\
(\mathrm{Ha})\end{array}$ & $\begin{array}{c}\text { Produksi } \\
(\mathrm{Ton})\end{array}$ & $\begin{array}{c}\text { Produktivitas } \\
\left(\mathrm{Kg} \mathrm{Ha}^{-1}\right)\end{array}$ \\
\hline 1 & Batanghari & 29 & 17 & 630 \\
2 & Muaro jambi & 156 & 11 & 133 \\
3 & Bungo & 112 & 33 & 516 \\
4 & Tebo & 198 & 21 & 143 \\
5 & Merangin & 267 & 52 & 299 \\
6 & Sorolangun & 243 & 26 & 220 \\
7 & Tanjung jabung barat & 9.882 & 10,515 & 1.434 \\
8 & Tanjung jabung timur & 8.894 & 2,745 & 440 \\
9 & Kerinci & 121 & 22 & 407 \\
10 & Kota sungai penuh & 67 & 37 & 881 \\
\hline & Jumlah/Total & 19.969 & 13.482 & 944 \\
\hline
\end{tabular}

Sumber:Dinas Perkebunan Provinsi Jambi, 2015

Tanaman Pinang di Provinsi Jambi banyak dikembangkan secara tumpang sari dengan tanaman yang lain seperti dengan tanaman Kelapa Dalam dengan jarak tanam $\pm 3 \times 3 \mathrm{~m}$ (populasi \pm 1000 tanaman per ha). Areal pengembangan terluas terdapat di wilayah pantai timur, yaitu di Kabupaten Tanjung Jabung Timur seluas 7.146 Ha (Dinas Perkebunan Provinsi Jambi, 2015).

Tumpang sari Pinang dengan Kelapa Dalam merupakan sebuah kombinasi efektif untuk pemanfaatan lahan. Penanaman Pinang dapat dilakukan di antara barisan Kelapa Dalam yang sesuai dengan syarat tumbuhnya maka akan memberikan dampak yang yang baik sehingga menghasilkan pertumbuhan dan produksi yang optimal (Muin, 2015).

Untuk mengetahui produktivitas lahan pada sistem tumpang sari digunakan nilai nisbah kesetaraan lahan (NKL). Menurut Pronowo (2016), NKL adalah jumlah nisbah hasil antara tanaman yang ditumpangsarikan terhadap hasil tanaman yang ditanam secara tunggal pada tingkat manajemen yang sama. NKL merupakan salah satu cara yang digunakan untuk menghitung produktivitas lahan dari dua atau lebih tanaman yang ditumpangsarikan.

\section{METODE PENELITIAN}

Penelitian dilakukan di kelurahan Sabak Ulu serta di desa Siao Dalam kecamatan Muara Sabak Timur kabupaten Tanjung Jabung Timur dengan kondisi lahan gambut tipe luapan D.

Bahan yang digunakan adalah pertanaman Pinang yang berumur 10-11 tahun yang ditumpangsarikan dengan Kelapa Dalam yang berumur 10-12 tahun. Alat yang digunakan meliputi Global Positioning Services (GPS), meteran, timbangan, lembar kuisioner, alat perekam, dan kamera. 
Jurnal Media Pertanian Vol. 3 No. 1 Tahun 2018 Hal. 1 - 9

Media Komunikasi Hasil Penelitian dan Review Literatur Bidang Ilmu Agronomi ISSN print $2503-1279$

ISSN online $2581-1606$

Penelitian ini menggunakan metode survey pada lahan-lahan petani yang ditanami Pinang monokultur dan Pinang ditumpangsarikan dengan Kelapa Dalam. Lokasi penelitian ini dipilih secara sengaja, lokasi-lokasi tersebut memiliki lahan budidaya tumpang sari Pinang dengan Kelapa Dalam.

Metode pengambilan sampel menggunakan metode SRS (simple random sampling). Jumlah tanaman sampel untuk Pinang tumpang sari sebanyak 60 batang per ha x $3=180$ batang ( $15 \%$ dari 400 batang per ha), jumlah tanaman sampel untuk Pinang tunggal sebanyak 50 batang per ha x $3=150$ batang $(10 \%$ dari 500 batang per ha), jumlah tanaman sampel untuk Kelapa Dalam tumpang sari sebanyak 21 batang per ha x $3=63$ batang ( $15 \%$ dari 140 batang per ha) dan jumlah tanaman sampel untuk Kelapa Dalam tunggal sebanyak 23 batang per ha $\mathrm{x}$ $3=69$ batang ( $15 \%$ dari 150 batang per ha). Tanaman sampel dipilih secara sengaja dan lokasi tanaman yang dijadikan sampel dicatat titik koordinatnya menggunakan GPS.

Parameter yang diamati meliputi jarak tanam (m), tinggi tanaman (m), lingkar batang $(\mathrm{cm})$, umur mulai produksi (th), produktivitas buah Pinang dan Kelapa secara tumpang sari (ton per ha), produktivitas Pinang dan Kelapa tunggal (ton per ha), dan produktivitas lahan (NKL). Untuk menjawab hipotesis yang diajukan, data di analisis secara deskriptif dalam bentuk tabulasi.

\section{Jarak Tanam (m)}

\section{HASIL DAN PEMBAHASAN}

Jarak tanam tanaman Pinang dan Kelapa Dalam tunggal diukur antar tanaman pokok pada setiap sampel tanaman Hasil pengukuran jarak tanam dapat dilihat pada Tabel 3 .

Tabel 3. Rata-rata jarak tanam Pinang dan Kelapa Dalam pada sistem tumpang sari dan sistem tunggal

\begin{tabular}{cc|cc}
\hline \multicolumn{4}{c}{ Jarak Tanam $(\mathrm{m})$} \\
\hline \multicolumn{3}{c}{ Tumpang Sari } & \multicolumn{2}{c}{ Tunggal } \\
\hline Pinang & Kelapa Dalam & Pinang & Kelapa Dalam \\
$4 \times 4$ & $8,30 \times 8$ & $4 \times 3$ & $8 \times 8$ \\
\hline
\end{tabular}

Hasil penelitian menunjukkan bahwa jarak tanam Pinang atau Kelapa Dalam tumpang sari lebih lebar dibandingkan dengan jarak tanam Pinang atau Kelapa Dalam tunggal. Jarak tanam Pinang tumpang sari 4 x 4 m sedangkan jarak tanam Pinang tunggal $4 \times 3 \mathrm{~m}$, ini menunjukkan jarak tanam Pinang tumpang sari lebih lebar sebesar $1 \mathrm{~m}$ dibandingkan Pinang tunggal. Untuk jarak tanam Kelapa Dalam tumpang sari $8,30 \times 8 \mathrm{~m}$ sedangkan Kelapa Dalam tunggal $8 \times 8 \mathrm{~m}$, ini juga menunjukkan bahwa jarak tanam Kelapa Dalam tumpang sari lebih lebar sebesar $30 \mathrm{~cm}$ dibandingkan kelapa dalam tunggal.

\section{Tinggi Tanaman (m)}

Rata-rata tinggi tanaman Pinang dan Kelapa Dalam pada sistem tumpang sari dan penanaman tunggal dirangkum pada Tabel 4. 
Jurnal Media Pertanian Vol. 3 No. 1 Tahun 2018 Hal. 1 - 9

Media Komunikasi Hasil Penelitian dan Review Literatur Bidang Ilmu Agronomi ISSN print $2503-1279$

ISSN online $2581-1606$

Tabel 4. Rata-rata tinggi tanaman Pinang dan Kelapa Dalam pada sistem tumpang sari dan sistem tunggal

\begin{tabular}{c|c|c}
\hline \multicolumn{3}{c}{ Tinggi Batang $(\mathrm{m})$} \\
\hline Tanaman & Tumpang Sari & Tunggal \\
\hline Pinang & 10,62 & 10,12 \\
Kelapa Dalam & 8,11 & 9,28 \\
\hline
\end{tabular}

Dilihat dari pertumbuhan tanaman Pinang tumpang sari, pertumbuhan tanaman lebih tinggi dibandingkan dengan Pinang sistem tunggal. Hal ini terlihat bahwa rata-rata tinggi tanaman Pinang tumpang sari 10,62 m sedangkan tinggi tanaman Pinang tunggal $10,12 \mathrm{~m}$. Populasi tanaman yang banyak pada sistem tumpang sari membuat tajuk tanaman Pinang dan tajuk Kelapa Dalam saling menaungi, mengakibatkan terjadinya persaingan mendapatkan sinar matahari yang dibutuhkan untuk proses fotosintesis. Persaingan antar tanaman membuat tanaman Pinang kekurangan sinar matahari, akibatnya tanaman Pinang cepat meninggi. Hal ini sejalan dengan pendapat Ndarat (2007), tanaman yang kekurangan sinar matahari akan mengalami pertumbuhan tinggi yang lebih cepat dibandingkan dengan tanaman yang kebutuhan sinar mataharinya terpenuhi.

\section{Lingkar Batang (cm)}

Rata-rata perbedaan lingkar batang tanaman Pinang dan Kelapa Dalam pada sistem tumpang sari dan penanaman tunggal dapat dilihat pada Tabel 5.

Tabel 5 Rata-rata lingkar batang Pinang dan Kelapa Dalam pada sistem tumpang sari dan sistem tunggal

\begin{tabular}{c|c|c}
\hline \multicolumn{3}{c}{ Lingkar Batang $(\mathrm{cm})$} \\
\hline Tanaman & Tumpang Sari & Tunggal \\
\hline Pinang & 43,26 & 42,84 \\
Kelapa Dalam & 91,55 & 89,37 \\
\hline
\end{tabular}

Hasil penelitian menunjukkan bahwa lingkar batang Pinang atau Kelapa Dalam tumpang sari lebih besar dibandingkan lingkar batang Pinang atau Kelapa dalam tunggal. Rata-rata lingkar batang Pinang tumpang sari 43,26 cm sedangkan rata-rata lingkar batang Pinang tunggal $42,84 \mathrm{~cm}$, hal ini menunjukkan bahwa rata-rata lingkar batang Pinang tumpang sari lebih besar $0,42 \mathrm{~cm}$ dibandingkan dengan rata-rata Pinang tunggal. Rata-rata lingkar batang Kelapa Dalam tumpang sari 91,55 cm sedangkan rata-rata lingkar batang Kelapa Dalam tunggal 89,37 cm, ini menunjukkan adanya perbedaan rata-rata lingkar batang antara Kelapa Dalam tumpang sari dengan Kelapa Dalam tunggal sebesar 2,18 cm.

\section{Umur Mulai Produksi (tahun)}

6.

Umur mulai produksi Pinang dan Kelapa Dalam dapat dilihat pada Tabel

Tabel 6. Rata-rata umur mulai berproduksi tanaman Pinang dan Kelapa Dalam pada sistem tumpang sari dan sistem tunggal

\begin{tabular}{c|c|c}
\hline \multicolumn{3}{c}{ Umur Mulai Produksi (tahun) } \\
\hline Tanaman & Tumpang Sari & Tunggal \\
\hline Pinang & 4 & 3,5 \\
Kelapa Dalam & 7 & 6,5 \\
\hline \hline
\end{tabular}

Diterbitkan oleh Program Studi Agroteknologi Fakultas Pertanian Universitas Batanghari Jambi Halaman 5 
Jurnal Media Pertanian Vol. 3 No. 1 Tahun 2018 Hal. 1 - 9

Media Komunikasi Hasil Penelitian dan Review Literatur Bidang Ilmu Agronomi ISSN print $2503-1279$

ISSN online $2581-1606$

Hasi penelitian menunjukkan terdapat perbedaan umur mulai produksi antara tanaman Pinang atau Kelapa Dalam tumpang sari dengan tanaman Pinang atau Kelapa Dalam tunggal. Pinang tumpang sari mulai berproduksi pada umur 4 tahun sedangkan Pinang tunggal mulai berproduksi pada umur 3,5 tahun, hal ini menunjukkan tanaman Pinang tumpang sari lebih lambat dalam berproduksi. Kelapa Dalam tumpang sari mulai berproduksi pada umur 7 tahun sedangkan Kelapa Dalam tunggal mulai berproduksi umur 6,5 tahun, hal ini menunjukkan tanaman Kelapa Dalam tumpang sari lebih lambat dalam berproduksi. Jumlah populasi yang terlalu banyak pada sistem tumpang sari, mengakibatkan tanaman berkompetisi dalam penyerapan unsur hara, air dan cahaya. Kompetisi yang terjadi menyebabkan kebutuhan tanaman untuk berproduksi terganggu, akibatnya tanaman akan sedikit terhambat dalam proses produksi.

\section{Produktivitas (ton ha ${ }^{-1}$ )}

Perbedaan produksi tanaman Pinang dan tanaman Kelapa Dalam sistem tumpang sari dan sistem tunggal dapat dilihat pada Tabel 7.

Tabel 7. Rata-rata produktivitas buah Pinang dan Kelapa Dalam pada sistem tumpang sari dan sistem tunggal (ton $\mathrm{ha}^{-1}$ )

\begin{tabular}{ccc}
\multicolumn{3}{c}{ tumpang sari dan sistem tunggal $\left(\right.$ ton ha $\left.{ }^{-1}\right)$} \\
\hline \multicolumn{3}{c}{ Produktivitas $\left(\right.$ ton $\left.\mathrm{ha}^{-1}\right)$} \\
\hline Tanaman & Tumpang Sari & Tunggal \\
\hline Pinang & 0,12 & 0,16 \\
Kelapa Dalam & 0,68 & 0,95 \\
\hline
\end{tabular}

Hasil penelitian menunjukkan bahwa produksi tanaman Pinang yang ditumpangsarikan dengan Kelapa Dalam lebih rendah dibanding dengan tanaman Pinang dan Kelapa Dalam secara tunggal. Hal ini terjadi karena pada sistem tumpang sari populasi tanaman lebih banyak (melebihi populasi optimum) sehingga akan terjadi persaingan interspesifik dalam hal penyerapan unsur hara dan air dalam tanah. Persaingan yang ditimbulkan antara tanaman yang satu dengan lainnya adalah tanaman saling hambat dalam penyerapan makanan sehingga memunculkan interrelasi kompetitif yang mengakibatkan salah satu tanaman tertekan atau kedua tanaman mengalami tekanan. Dari data yang diperoleh, produksi tanaman Pinang tumpang sari 0,12 ton $\mathrm{ha}^{-1}$, Kelapa Dalam tumpang sari 0,68 ton $\mathrm{ha}^{-1}$, Pinang tunggal 0,16 ton ha ${ }^{-1}$ dan Kelapa Dalam tunggal 0,95 ton ha $^{-1}$. Hasil ini menunjukkan bahwa pada sistem tumpang sari tanaman Pinang dan Kelapa Dalam sama-sama tertekan yang ditunjukkan oleh produksi yang berbeda dengan tanaman Pinang dan Kelapa Dalam pada sistem tunggal. Jika dibandingkan dengan produktivitas tanaman Pinang di kabupaten Bungo 0,33 ton $\mathrm{ha}^{-1}$ menunjukkan bahwa produktivitas tanaman buah Pinang hasil penelitian lebih rendah. Untuk produktivitas tanaman Kelapa Dalam menunjukkan hasil yang lebih tinggi dibandingkan dengan produktivitas tanaman Kelapa Dalam di kabupaten Bungo, yaitu 0,65 ton ha ${ }^{-1}$.

\section{Produktivitas lahan}

Berdasarkan estimasi produksi dapat diketahui produktivitas lahan pada penanaman tumpangsari dengan nilai NKL sebagai berikut ; 
Jurnal Media Pertanian Vol. 3 No. 1 Tahun 2018 Hal. 1 - 9

Media Komunikasi Hasil Penelitian dan Review Literatur Bidang Ilmu Agronomi

ISSN print $2503-1279$ ISSN online $2581-1606$

$$
\begin{aligned}
\mathrm{NKL} & =\frac{X c}{x o}+\frac{Y c}{\mathrm{Yo}} \\
\mathrm{NKL} & =\frac{0,12}{0,16}+\frac{0,68}{0,95} \\
& =0,75+0,71 \\
& =1,46
\end{aligned}
$$

Keterangan :

NKL = Nisbah Kesetaraan Lahan

$\mathrm{Xc} \quad=$ Hasil Pinang pada pertanaman tumpangsari

Xo = Hasil Pinang pada pertanaman tunggal Pinang

$\mathrm{Yc} \quad=$ Hasil Kelapa dalam pada pertanaman tumpangsari

Yo $\quad=$ Hasil Kelapa dalam pada pertanaman tunggal Kelapa dalam

Hasil penelitian menunjukkan produksi tanaman tumpang sari lebih rendah dibandingkan dengan sistem tunggal. Tetapi dari hasil perhitungan nilai nisbah kesetaraan lahan diperoleh nilai NKL 1,46. Hal ini menggambarkan sistem tumpang sari lebih menguntungkan sebesar $46 \%$ dari sistem tunggal. Sistem tumpang sari lebih menguntungkan karena dalam satuan luas lahan yang sama dengan sistem tunggal menghasilkan lebih dari satu jenis produksi tanaman. NKL merupakan salah satu cara menghitung produktivitas lahan yang ditanami 2 atau lebih tanaman yang ditumpangsarikan. Sistem tumpang sari akan lebih menguntungkan jika NKL lebih dari 1, apabila nilai NKL sama dengan 1 menunjukkan bahwa pola tanam sistem tumpang sari dan sistem tunggal memberikan keuntungan yang sama. Sejalan dengan pendapat Yuwariah, Ruswandi, dan Irwan. (2017) yang menyatakan bahwa nilai rata-rata NKL yang besar dari 1 menggambarkan bahwa pertanaman campuran menguntungkan jika ditanam secara tumpang sari dibanding pertanaman tunggal pada luas lahan yang sama. 
Jurnal Media Pertanian Vol. 3 No. 1 Tahun 2018 Hal. 1 - 9

Media Komunikasi Hasil Penelitian dan Review Literatur Bidang Ilmu Agronomi ISSN print 2503 - 1279

ISSN online $2581-1606$

\section{Model Pola Tanam Tumpang Sari Pinang dengan Kelapa Dalam}

1. Model pola tanam tumpang sari Pinang dengan Kelapa Dalam di lapangan

Keterangan :
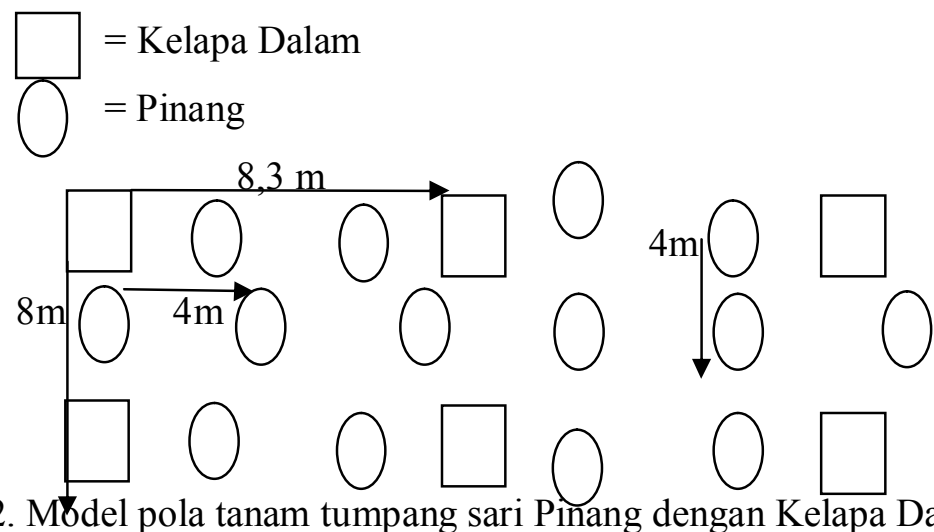

2. Mơdel pola tanam tumpang sari Pinang dengan Kelapa Dalam yang di sarankan

B
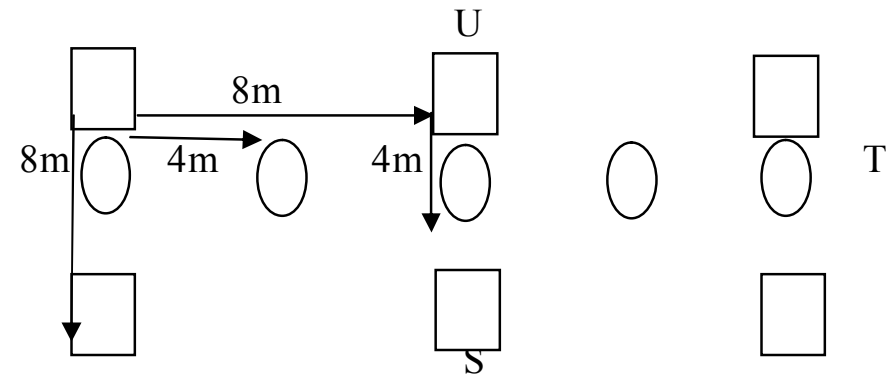

Ket : $\mathrm{B}=$ barat

$$
\begin{aligned}
& \mathrm{T}=\text { timur } \\
& \mathrm{U}=\text { utara } \\
& \mathrm{S}=\text { selatan }
\end{aligned}
$$

Model tumpang sari Pinang dengan Kelapa Dalam di lapangan memiliki populasi tanaman 625 batang, sedangkan model tumpang sari Pinang dengan Kelapa Dalam yang disarankan hanya memiliki populasi 468 batang. Hal ini menunjukkan adanya perbedaan jumlah populasi pada kedua pola tanam ini sebesar 157 batang. Populasi yang lebih sedikit pada model tumpang sari yang disarankan memungkinkan persaingan tanaman dalam penyerapan unsur hara, air dan sinar matahari lebih rendah dibandingkan dengan model tumpang sari di lokasi penelitian.

\section{Kesimpulan}

\section{KESIMPULAN DAN SARAN}

Dari hasil penelitian dapat ditarik kesimpulan sebagai berikut :

1. Produksi tanaman Pinang dan Kelapa Dalam sistem tunggal lebih besar dari sistem tumpang sari. Namun berdasarkan perhitungan nilai nisbah kesetaraan 
Jurnal Media Pertanian Vol. 3 No. 1 Tahun 2018 Hal. 1 - 9

Media Komunikasi Hasil Penelitian dan Review Literatur Bidang Ilmu Agronomi

ISSN print $2503-1279$

ISSN online $2581-1606$

lahan (NKL) menunjukan nilai lebih dari $1(1,46)$, menggambarkan bahwa sistem tumpang sari lebih menguntungkan dibandingkan sistem tunggal.

2. Model pola tanam tumpang sari yang lebih baik adalah model 2 .

\section{Saran}

Diharapkan petani yang bercocok tanam Pinang sistem tumpang sari dengan Kelapa Dalam agar memperhitungkan jarak tanam mengikuti pola tanam tumpang sari model 2 .

\section{DAFTAR PUSTAKA}

Dinas Pertanian Tanaman Pangan Provinsi Jambi, 2014. Profil Usaha Tani di Provinsi Jambi.

Dinas Perkebunan Provinsi Jambi, 2015. Statistik Perkebunan Provinsi Jambi Tahun 2015.

Dinas Perkebunan Provinsi Jawa Timur, 2012. Budidaya Tanaman Kelapa..

Direktorat Jendral Perkebunan, 2015. Statistik Perkebunan Indonesia 2013-2015. Jakarta. Direktorat Jendral Perkebunan.

Muin. M. 2015. Petani dan Permasalahan Petani. Rajawali Press. Jakarta.

Ndarat, J. 2007. Kesejahteraan dan Kesempatan Kerja Petani. Jakarta Press. Jakarta.

Pronowo. D . 2016 Budidaya Tanaman Perkebunan. Universitas Sebelas Maret

Wirakusumah, S. 2003. Dasar-Dasar Ekologi Bagi Populasi dan Komunitas. UI-Press. Jakarta

Yuwariah,Y.D. Ruswandi, A.W. Irwan. 2017. Pengaruh Pola Tanam Tumpangsari Jagung Dan Kedelai Terhadap Pertumbuhan Dan Hasil Jagung Hibrida Dan Evaluasi Tumpangsari Di Arjasari Kabupaten Bandung. Jurnal Kultivasi Vol. 16 (3) Desember 2017 